\title{
Evidence-based review of data on the combination inhaler umeclidinium/vilanterol in patients with COPD
}

This article was published in the following Dove Press journal: International Journal of Chronic Obstructive Pulmonary Disease

\author{
Timothy E Albertson ${ }^{1,2}$ \\ Willis S Bowman ${ }^{1,2}$ \\ Richart W Harper ${ }^{1,2}$ \\ Regina M Godbout ${ }^{2,3}$ \\ Susan Murin ${ }^{1,2}$ \\ 'Department of Internal Medicine, \\ Division of Pulmonary, Critical Care and \\ Sleep Medicine, UC Davis, Sacramento, \\ CA, USA; ${ }^{2}$ Department of Veterans \\ Affairs, Northern California Health Care \\ System, Mather, CA, USA; ${ }^{3}$ Department \\ of Internal Medicine, Division of General \\ Medicine, UC Davis, Sacramento, \\ CA, USA
}

Correspondence: Timothy E Albertson Department of Internal Medicine, Division of Pulmonary, Critical Care and Sleep Medicine, UC Davis, Patient Support Services Building, 4I50 V Street, suite 3100, Sacramento, CA 95817, USA Email tealbertson@ucdavis.edu

\begin{abstract}
The use of inhaled, fixed-dose, long-acting muscarinic antagonists (LAMA) combined with long-acting, beta ${ }_{2}$-adrenergic receptor agonists (LABA) has become a mainstay in the maintenance treatment of chronic obstructive pulmonary disease (COPD). One of the fixed-dose LAMA/LABA combinations is the dry powder inhaler (DPI) of umeclidinium bromide (UMEC) and vilanterol trifenatate (VI) $(62.5 \mu \mathrm{g} / 25 \mu \mathrm{g})$ approved for once-a-day maintenance treatment of COPD. This paper reviews the use of fixed-dose combination LAMA/LABA agents focusing on the UMEC/VI DPI inhaler in the maintenance treatment of COPD. The fixed-dose combination LAMA/LABA inhaler offers a step beyond a single inhaled maintenance agent but is still a single device for the COPD patient having frequent COPD exacerbations and persistent symptoms not well controlled on one agent. Currently available clinical trials suggest that the once-a-day DPI of UMEC/VI is well-tolerated, safe and non-inferior or better than other currently available inhaled fixeddose LAMA/LABA combinations for COPD.
\end{abstract}

Keywords: fixed-dose combination inhalers, long-acting beta ${ }_{2}$-adrenergic agonists, LABA, long-acting muscarinic antagonists, LAMA, COPD, umeclidinium bromide, vilanterol trifenatate

\section{Introduction}

Chronic obstructive pulmonary disease (COPD) is a syndrome caused by a combination of host factors, genetic susceptibilities and environmental exposures to injurious agents like tobacco smoke. It is characterized by poorly reversible airway constriction, chronic inflammation, and structural changes leading to loss of elastic recoil and air trapping. ${ }^{1}$ COPD is a leading cause of death, disability, and health-care costs. As a syndrome, it presents with many different phenotypes. Along with inhaled corticosteroids (ICS), bronchodilators including short-acting

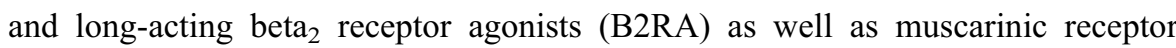
antagonists (MRA) play an important role in the treatment of the various COPD phenotypes. Recent reviews and meta-analyses have concluded that the combination of a fixed-dose, long-acting B2RA (LABA) combined with a long-acting MRA (LAMA) is an effective strategy for improving and maintaining lung function in COPD patients. ${ }^{2-5}$

Two reports, including a systematic review and meta-analysis and a Cochrane systematic review, have concluded that the use of a fixed-dose combination (FDC) inhaler that includes a LAMA and LABA results in fewer COPD exacerbations than 
a LAMA alone or a FDC of ICS with a LABA. ${ }^{6,7}$ The first systematic review and meta-analysis evaluated 18 studies (making up a total of 23 trials) with a total of 20,185 patients. $^{6}$ Trough forced expiratory volume in 1 second $\left(\mathrm{FEV}_{1}\right)$ at week 12 was significantly improved by the use of combined FDC LAMA/LABA compared to either a LAMA alone or a FDC ICS/LABA $(0.07 \mathrm{~L}$ and $0.08 \mathrm{~L}$, respectively, both $P<0.0001)$. The FDC LABA/LAMA significantly $(P<0.0001)$ improved dyspnea scores compared to a LAMA alone but not compared to the FDC ICS/LABA at 12 weeks. Severe to moderate COPD exacerbations were reduced with the FDC LABA/LAMA compared to the FDC LABA/ICS (rate ratio (RR) 0.82, 95\% CI, 0.75-0.91). The FDC LABA/LAMA significantly reduced rescue medication use compared to both the LAMA alone $(P<0.001)$ and the FDC ICS/LABA $(P=0.001)$. There was no difference in adverse events (AE) incidence between LAMA/LABA and LAMA alone but when LAMA/LABA was compared to ICS/ LABA there was a lower AE incidence (RR 0.94, 95\% CI, 0.89-0.99). A marked reduction in pneumonia risk was seen with the FDC LAMA/LABA compared to FDC ICS/LABA (RR 0.59, 95\% CI, 0.43-0.81).

The Cochrane review included 11 studies and 9,839 patients with COPD. ${ }^{7}$ The studies ranged from 6 to 52 weeks and compared the use of FDC LAMA/LABA to FDC ICS/LABA treatments. A reduction in COPD exacerbations was found comparing FDC LAMA/LABA to FDC ICS/LABA (OR 0.82, 95\% CI 0.70-0.96) and an increase in trough $\mathrm{FEV}_{1}$ from baseline with a mean of $0.08 \mathrm{~L}(95 \%$ CI $0.06-0.09, P<0.0001)$ was seen. The risk of pneumonia was again lower with the use of FDC LAMA/LABA compared to FDC ICS/LABA (OR 0.57 , 95\% CI, 0.42-0.79, $P=0.0006$ ).

Several studies have explored withdrawing an ICS in stable patients with moderate to severe COPD. ${ }^{8,9}$ Magnussen et $\mathrm{al}^{8}$ studied 2,485 COPD patients with a history of COPD exacerbations in a 12-month, doubleblind, parallel-group study. Patients were placed on a LAMA, ICS, and LABA for a six-month run-in period called the WISDOM Trial. They were then randomized to continue the triple therapy or to the withdrawal of just the ICS and were to continue the LAMA and LABA inhaler over the 12 weeks of the study. There was no significant difference in the rate of COPD exacerbation with the study meeting the prespecified noninferiority criterion. The trough $\mathrm{FEV}_{1}$ was $0.038 \mathrm{~L}$ greater $(P<0.001)$ in the glucocorticoid-withdrawal group but this difference is unlikely to be clinically important. The rate of pneumonia was
$5.8 \%$ for those that continued triple inhaled therapy and $5.5 \%$ for those that had the ICS withdrawal. ${ }^{8}$

A more recent study of COPD patients with infrequent exacerbations but who had been on long-term triple (LAMA, LABA, ICS) therapy were randomized to remove the ICS. $^{9}$ This 26 -week, randomized, doubleblind, triple-dummy study was of 1,053 COPD patients who were switched from their baseline medication to indacaterol (IND)/glycopyrronium (GLY) 110/50 $\mu \mathrm{g}$ via Breezhaler $^{\circledR}$ once daily or $18 \mu \mathrm{g}$ tiotropium (TIO) once daily by Handihaler ${ }^{\circledR}$ plus salmeterol (SAL)/fluticasone propionate (FP) 50/500 $\mu \mathrm{g}$ twice-a-day and appropriate dummy inhalers at appropriate frequencies. The withdrawal of ICS resulted in a trough $\mathrm{FEV}_{1}$ reduction of (-) $0.026 \mathrm{~L}(95 \% \mathrm{CI},(-) 0.051-(+) 0.001 \mathrm{~L})$. The annualized rate of moderate or severe COPD exacerbations was not different between treatment groups (RR 1.08, 95\% CI, $0.83-1.40)$. Of interest, a pre-specified analysis of patients with elevated blood eosinophils ( $\geq 300$ cells $/ \mu \mathrm{L}$ ) found that they were at increased risk of COPD exacerbations after withdrawal of ICS compared to those that stayed on the ICS (RR 1.86, 95\% CI, 1.06-3.29). ${ }^{9}$

Exploring the COPD phenotype with elevated eosinophils, Cheng ${ }^{10}$ analyzed five studies with 12,496 COPD patients with moderate-to-very severe COPD. At baseline about $60 \%$ of these COPD patients had $\geq 2 \%$ blood eosinophils. The results of the meta-analysis included a $17 \%$ reduction of moderate-severe COPD exacerbation rates with ICS therapy in patients with eosinophils $>2 \%$ (RR $1.969,95 \% \mathrm{CI}, 0.97-0.99, P=0.03$ ) and no advantage to ICS therapy in those patients with baseline eosinophil counts of $<2 \% \quad$ (RR 1.29, 95\% CI, 0.888-1.879, $P<0.181)$. Both elevated eosinophils and IL-4 levels have been found to be associated with subsequent development of the asthma COPD overlap syndrome (ACOS) in firefighters previously exposed to the World Trade Center Collapse. ${ }^{11}$ A high degree of bronchodilator responsiveness, history of atopy, IgE documented sensitivity to $\geq 1$ airborne allergen, increased exhaled nitric oxide and previous diagnosis of asthma when less than 40 years old and elevated blood and sputum eosinophils have been used to diagnose ACOS in COPD patients. ${ }^{12}$

\section{Fixed-dose combination dry-powder inhaler of umeclidinium and vilanterol}

The LAMA umeclidinium bromide (UMEC) and the LABA vilanterol trifenate (VI), both delivered as a once-a-day 
DPI, have been independently shown to be effective maintenance treatments for COPD. ${ }^{13-20}$ Unlike UMEC, VI is not commercially available as a single-agent inhaler but is only available combined with UMEC and/or the ICS fluticasone furoate (FF).

A direct 12-week, multiple-centered, open-label, parallel-group study in COPD patients compared UMEC $(62.5 \mu \mathrm{g})$ DPI using the Ellipta ${ }^{\circledR}$ device to glycopyrronium $(50 \mu \mathrm{g})$ by DPI using the Breezhaler ${ }^{\circledR}$ device once daily. ${ }^{15}$ Improvements in all endpoints including day 85 trough $\mathrm{FEV}_{1}$ and adverse events were similar in the 1,037 randomized patients. Another randomized, blind, multiplecentered, parallel-group, non-inferiority, 12-week study compared once-daily UMEC $(62.5 \mu \mathrm{g})$ plus placebo to once-daily TIO $(18 \mu \mathrm{g})$ plus placebo both by DPI. ${ }^{17}$ A total of 1,017 COPD patients were randomized and the change from baseline at Day 85 trough $\mathrm{FEV}_{1}$ was greater with UMEC compared to TIO $(0.053 \mathrm{~L}, 95 \% \mathrm{CI}$, 0.025-0.08 L, $P<0.001)$. This superior efficacy of UMEC compared to TIO was associated with a similar safety and adverse events profile.

\section{Review and methodology}

The Food and Drug Administration (FDA) website accessdata.gov was used to determine their approved inhalers. Inhalers approved by the European Medicines Agency (EMA) were confirmed using the https://www.ema. europa.eu website and Canadian approved drugs were confirmed using the website health-products.canada.ca.

Because of several new trials since the last review, a new extensive review of LAMA, LABA/LAMA, VI, vilanterol, UMEC, umeclidinium, and COPD was performed using https:/www.ncbi.nlm.nih.gov/pubmed and https://scholar.google.com. Papers found were also crossreferenced for additional clinical trials of UMEC/VI inhaled treatment and COPD. In addition, completed and published clinical trials with UMEC/VI and COPD were reviewed at https://clinicaltrials.gov. Several new trials using UMEC/VI in COPD were found since the last reviews and both older clinical trials and these newer trials are included in this summary.

\section{Pharmacology, pharmacokinetics, and safety of UMEC/VI}

Using uninvolved human airways obtained during lobectomies for lung cancer, Calzetta et $\mathrm{al}^{21}$ found that at the current concentrations of presumed airway delivery with
UMEC/VI (62.5/25 $\mu \mathrm{g})$, the concentration-dependent relaxation of isolated bronchi is significantly greater with UMEC compared to the dose of VI $(P<0.05)$. This in vitro finding of UMEC resulting in greater airway relaxation has not predicted clinical efficacy in COPD patients. A similar study of tracheal tissue from otherwise healthy lungtransplant donors treated the tracheal tissue with either VI, UMEC, UMEC and VI or controls (salmeterol, propranolol, ICI 118.551 or methacholine) and evaluated the effects on cyclic adenosine monophosphate (cAMP) levels and extracellular free calcium $\left(\left[\mathrm{CA}^{2+}\right]_{\mathrm{i}}\right){ }^{22}$ Both VI and salmeterol (SAL) generated increases in cAMP from human airway smooth muscle cells. With beta $_{2}$ receptor (B2R) antagonists propranolol and ICI 118.551, the VIinduced cAMP increases were inhibited in a concentration-dependent fashion. Human airway cells stimulated by methacholine also resulted in increased $\left[\mathrm{CA}^{2+}\right]_{\mathrm{i}}$ release that was greater in the presence of both UMEC + VI than UMEC alone. VI also induced the regulator of G-protein signaling 2-messenger RNA expression and this was also further enhanced by UMEC exposure. $^{22}$ This suggests a complex positive interaction between the LAMA UMEC and the LABA VI on human airway cells that contributes to bronchial relaxation.

Population pharmacokinetics of inhaled UMEC/VI were studied in patients for the efficacy trials NCT01313637 $7^{23}$ and NCT01313650 24 in COPD patients. Plasma concentration of UMEC and VI from more than 16,000 samples resulted in a two-compartment pharmacokinetic model with first-order absorption. ${ }^{25}$ Both increases in body weight and increasing age affected apparent inhaled clearance and the volume of distribution of the central compartment. Increased weight is associated with greater apparent inhaled clearance and with decreased volume of distribution of the central compartment for both UMEC and VI. Goyal et $\mathrm{al}^{25}$ also found that a $10 \%$ decrease in creatinine clearance resulted in a $3 \%$ decrease in the apparent inhaled clearance of UMEC. No UMEC and VI interactions were seen or modeled in this population pharmacokinetics study. ${ }^{25} \mathrm{~A}$ safety and pharmacokinetic study (NCT00976144) in 16 healthy, male, Japanese non-smokers evaluated single inhaled doses of placebo, UMEC $500 \mu \mathrm{g}$, VI $50 \mu \mathrm{g}$, and various combinations (placebo and placebo, UMEC $500 \mu \mathrm{g}$ and VI $50 \mu \mathrm{g}$ ) in four different sequences over four periods. ${ }^{26}$ The exposures were well tolerated with no trends observed in supine heart rates during the UMEC or VI maximum serum concentrations. ${ }^{26}$ 
Pharmacokinetic evaluations resulted in rapid absorption with maximum systemic levels for both VI and UMEC in about 5 min with rapid elimination and a halflife $\left(\mathrm{T}^{1} / 2\right)$ of $0.42(0.36-0.49)$ hours for VI and a $\mathrm{T}^{1} / 2$ of 1.56 (1.29-1.90) hours for UMEC and only a small amount of prolongation was noted when UMEC and VI were given together. The $T^{1} / 2$ of UMEC when given with VI was 1.78 (1.17-2.70) hours and that of VI when given with UMEC was $0.71(0.52-0.97)$ hours. ${ }^{26}$ Little drug interaction was demonstrated in single doses alone or in combination and clinically very high doses were well tolerated.

Another single-center trial of pharmacokinetics and safety (NCT01899638) evaluated healthy, non-smoking, male and female (1:1) Chinese subjects $(\mathrm{N}=20)$ with each subject getting a sequence of three of five treatments (UMEC/VI 62.5/25 $\mu \mathrm{g}$, UMEC/VI 125/25 $\mu \mathrm{g}$, UMEC $62.5 \mu \mathrm{g}$, UMEC $125 \mu \mathrm{g}$ or VI $25 \mu \mathrm{g}$ ) once daily for 10 days. ${ }^{27}$ The time to maximum serum VI levels was 0.08 hours after $25 \mu \mathrm{g}$ of VI regardless of UMEC dose $(0,62.5$ and $125 \mu \mathrm{g})$. The time to maximum UMEC serum level also was fast and similar at 0.08 hours after both doses with or without VI. No pharmacokinetic evidence of drug interaction was seen when UMEC and VI were given together. Twelve subjects had $\geq 1$ AEs with the most common being "chest discomfort." No vital sign or electrocardiogram abnormalities were noted. ${ }^{27}$ A 28-day, randomized, multicenter, double-blind, parallel-group, placebo-controlled trial of daily UMEC $(500 \mu \mathrm{g})$ in combination with VI $(25 \mu \mathrm{g})$ was performed in 51 male and female patients with COPD over the age of 40 years. ${ }^{28}$ UMEC/VI was non-inferior to placebo in weighted pulse rate determinations on Day 28 over hours $0-6$ post-dosing. There were no differences seen between UMEC/VI and placebo in blood pressure, minimum or maximum pulse rates or electrocardiogram QTc intervals. No correlations between maximum serum concentrations of either VI or UMEC and pulse rates on Day 28 were seen despite the very high UMEC dose. ${ }^{28}$

A pharmacokinetic study in nine patients with severe renal impairment (creatinine clearance $<30 \mathrm{~mL} /$ minute) matched to healthy volunteers and exposed to a single inhaled dose of UMEC $(125 \mu \mathrm{g})$ or UMEC/VI $(125 / 25 \mu \mathrm{g})$ did not demonstrate clinically relevant differences in VI or UMEC serum concentrations. ${ }^{29}$ Similarly, patients with moderate hepatic impairment were compared to normal volunteers (total $\mathrm{N}=18$ ) and given either a single dose of inhaled UMEC (125 $\mu \mathrm{g})$ or UMEC/VI $(125 / 25 \mu \mathrm{g})$ and then the other after a 7-14-day washout period. ${ }^{30}$ No significant differences in serum levels were seen between the patients with moderate liver disease and the normal volunteers. Dose adjustments of inhaled UMEC/VI do not appear to be indicated for COPD patients with renal or hepatic impairment.

An open-label study (NCT01128634) that randomized schedules evaluated the moderate $p$-glycoprotein transporter and cytochrome P450 isozyme 3A4 (CYP3A4) inhibitor verapamil in patients also given dry powder inhaled UMEC. UMEC serum levels and its safety profile were evaluated. ${ }^{31}$ Subjects $(\mathrm{N}=32)$ were healthy male and female non-smokers (18-65 years old). The subjects underwent two schedules of treatment. One was 8 days of UMEC $500 \mu \mathrm{g}$ inhaled daily alone followed by daily inhaled UMEC $500 \mu \mathrm{g}$ and a daily single oral tablet of $240 \mathrm{mg}$ verapamil for 5 days. The second schedule was similar to the first except that the subjects were exposed to inhaled UMEC/VI $(500 / 25 \mu \mathrm{g})$ daily for 8 days followed by continuation of UMEC/VI $(500 / 25 \mu \mathrm{g})$ and oral verapamil $240 \mathrm{mg}$ daily for 5 days. There was no increase in systemic levels of UMEC with VI compared to UMEC alone. Maximum UMEC serum concentrations were similar with or without verapamil exposure. The area under the curve for serum levels of UMEC increased by only 1.4-fold with verapamil compared to without. The combination of inhaled UMEC or UMEC/VI was well tolerated with or without daily exposure to the moderate $P$-glycoprotein transporter and CYP3A4 inhibitor verapamil. ${ }^{31}$

A comparison study of possible electrocardiogram and correlated QTc interval changes after exposure to the antibiotic moxifloxacin and to inhaled UMEC and UMEC/VI was performed. ${ }^{32}$ Male and female healthy non-smokers aged 18-65 years with normal electrocardiograms were included $(\mathrm{N}=103)$. Subjects received, randomly, four out of five possible treatments for 10 days including DPI UMEC $500 \mu \mathrm{g}+$ Day 10 placebo tablet, daily inhaled UMEC/VI $125 / 25 \mu \mathrm{g}$ + Day 10 placebo tablet, UMEC/VI 500/100 $\mu \mathrm{g}$ + Day 10 placebo tablet, placebo via Ellipta ${ }^{\circledR}$ DPI + Day 10 placebo tablet, and placebo inhaler + Day 10 moxifloxacin $400 \mathrm{mg}$ tablet. There were no clinically significant QTc interval changes noted during the 10 days with inhaled UMEC/VI $125 / 25 \mu \mathrm{g}$ or UMEC $500 \mu \mathrm{g}$ compared to placebo. The supra-therapeutic inhaled dose of UMEC/VI of $500 / 100 \mu \mathrm{g}$ was associated with a small change in corrected QTc interval of $6.4 \mathrm{~ms}(95 \% \mathrm{CI}, 4.3-8.5)$ at $10 \mathrm{~min}, 8.2 \mathrm{~ms}$ (95\% CI, 6.2-10.2) at $30 \mathrm{~min}$ and returned to placebo intervals rapidly after that time. This compares to a maximum change in corrected QTc interval of $9.7 \mathrm{~ms}(95 \% \mathrm{CI}$, 
$8.0-11.4)$ at $4 \mathrm{~h}$ after $400 \mathrm{mg}$ of oral moxifloxacin. ${ }^{32}$ No cardiac safety signal was noted in this study. The current data review is consistent with an earlier systematic review of the efficacy and safety of the fixed-dose combination DPI of UMEC/VI involving 11 trials from 10 studies $(9,609$ patients). It concluded that UMEC/VI had excellent evidence of efficacy and showed "superior efficacy" to its monocomponents, tiotropium and fluticasone/combination inhalers with "reduced" safety concerns compared to comparitors. ${ }^{33}$

The safety of fixed-dose LABA/LAMA inhalers has also been recently reviewed. ${ }^{34}$ The analysis of currently available data suggests a favorable cardiovascular safety profile for FDC LAMA/LABA inhalers in the COPD population. ${ }^{34}$ In the absence of new, larger, real-life and post-marketing studies to evaluate for rare low-frequency safety issues, FDC LAMA/LABA inhalers including UMEC/VI appear safe and efficacious.

\section{Clinical efficacy of fixed-dose combination inhaler UMEC/VI}

Based on the previously noted studies that demonstrated efficacy in COPD from both the LAMA UMEC and the LABA VI individually with a DPI device, it was logical and likely to improve drug adherence by putting these two compounds together into a single inhaler. The Ellipta ${ }^{\circledR}$ Inhaler was utilized. Table 1 summarizes most currently available fixed-dose combined B2RA and MRA inhalers and nebulized products used in the treatment of COPD.

Several reviews have summarized older clinical data on the dry-powder inhaled a fixed dose of UMEC/VI in COPD treatment. ${ }^{35-37}$ Similarly, a pooled analysis of older data of elderly patients with COPD showed efficacy of UMEC/VI in this group. ${ }^{38}$ The earliest studies (see Table 2) included several trials that explored both 62.5 and $125 \mu \mathrm{g}$ doses of UMEC combined with a $25 \mu \mathrm{g}$ dose of VI once-a-day in COPD patients..$^{23,39-41}$ These studies ranged from 12 to 52 weeks in duration and evaluated efficacy endpoints of forced expiratory volumes one second $\left(\mathrm{FEV}_{1}\right)$ weighted over the last day or trough $\mathrm{FEV}_{1}$ on the last day of the trial, exacerbation rates or use of rescue medication, and exercise endurance tests. Adverse events were also collected. Both doses of UMEC (62.5 and $125 \mu \mathrm{g})$, when combined with VI $(25 \mu \mathrm{g})$ demonstrated efficacy compared to placebo and VI alone (Table 2). Both doses of UMEC combined with VI resulted in improved week 12 exercise endurance testing and trough $\mathrm{FEV}_{1}$ compared to placebo. ${ }^{41}$ A study that directly compared UMEC $125 \mu \mathrm{g} / \mathrm{VI} 25 \mu \mathrm{g}$, UMEC $62.5 \mu \mathrm{g} / \mathrm{VI} 25 \mu \mathrm{g}$ and the LAMA tiotropium $18 \mu \mathrm{g}$ all delivered daily as a dry powder found both doses of UMEC combined with VI resulted in statistically $(P<0.001$ and $P<0.006$, respectively) greater Day 169 trough $\mathrm{FEV}_{1}$ compared to tiotropium alone. ${ }^{40}$ The magnitude of Day 169 trough $\mathrm{FEV}_{1}$ improvements was similar with UMEC/VI 125/25 $\mu \mathrm{g}(0.088 \mathrm{~L}(0.036-0.140))$ and UMEC/VI $62.5 / 25 \mu \mathrm{g}(0.090 \mathrm{~L}(0.039-0.140))$. The high $125 \mu \mathrm{g}$ dose of UMEC was not advanced to market.

After 2014, most of the published efficacy trials with the dry powder Ellipta $^{\circledR}$ inhaler and UMEC/VI have been solely with the $62.5 / 25 \mu \mathrm{g}$ dose (Table 2). The US Food and Drug Agency (FDA) approved the UMEC/VI $62.5 / 25 \mu \mathrm{g}$ dose as once-a-day maintenance therapy for COPD on 18 December 2013 as Anora Ellipta ${ }^{\circledR} .{ }^{42}$ Since 2014, only three studies compared UMEC/VI 62.5/25 $\mu \mathrm{g}$ to placebo. All patients in these placebo trials had access to asneeded albuterol or ipratropium inhalers in addition to either active or placebo maintenance inhalers. Siler et $\mathrm{al}^{43}$ showed that UMEC/VI improved Day 84 Saint George's respiratory questionnaire (SGRQ) results, reduced the number of puffs of a short-acting B2RA rescue inhaler needed per day, and improved the trough $\mathrm{FEV}_{1}$ compared to placebo. In the second placebo-controlled trial after 2014, Riley et al ${ }^{44}$ failed to show an improvement in exercise endurance test after 12 weeks of UMEC/VI $(62.5 / 25 \mu \mathrm{g})$ compared to placebo. The third trial was a 24 -week, phase III, multicenter, randomized, double-blind, placebo-controlled, parallel-group study evaluating UMEC/VI 125/25 $\mu \mathrm{g}$ and UMEC/VI 62.5/25 $\mu \mathrm{g}$ given as a once-daily inhalation versus placebo in patients of Asian ancestry with COPD. ${ }^{45}$ Both UMEC doses paired with VI demonstrated significant improvement in Day 169 trough $\mathrm{FEV}_{1}$ (both doses $P<0.001)$ and a significant reduction in rescue inhaler use compared to placebo (both $P<0.001$ ). A short, 14-day, triple-complete-block study where patients are exposed to all three treatments found UMEC/VI $(62.5 / 25 \mu \mathrm{g})$ more effective than VI $(25 \mu \mathrm{g})$ or UMEC $(62.5 \mu \mathrm{g})$ monotherapy. ${ }^{46}$ Those patients that showed $\mathrm{FEV}_{1}$ response to either VI or UMEC monotherapy were more likely to respond to UMEC/VI combination with greater improvement compared to either monotherapy.

The remaining efficacy trials in Table 2 demonstrated that once-a-day UMEC/VI $(62.5 / 25 \mu \mathrm{g})$ was better than a combined DPI of twice-a-day salmeterol/fluticasone propionate (50/250 or 50/500 $\mu \mathrm{g}$ combinations) in improving 


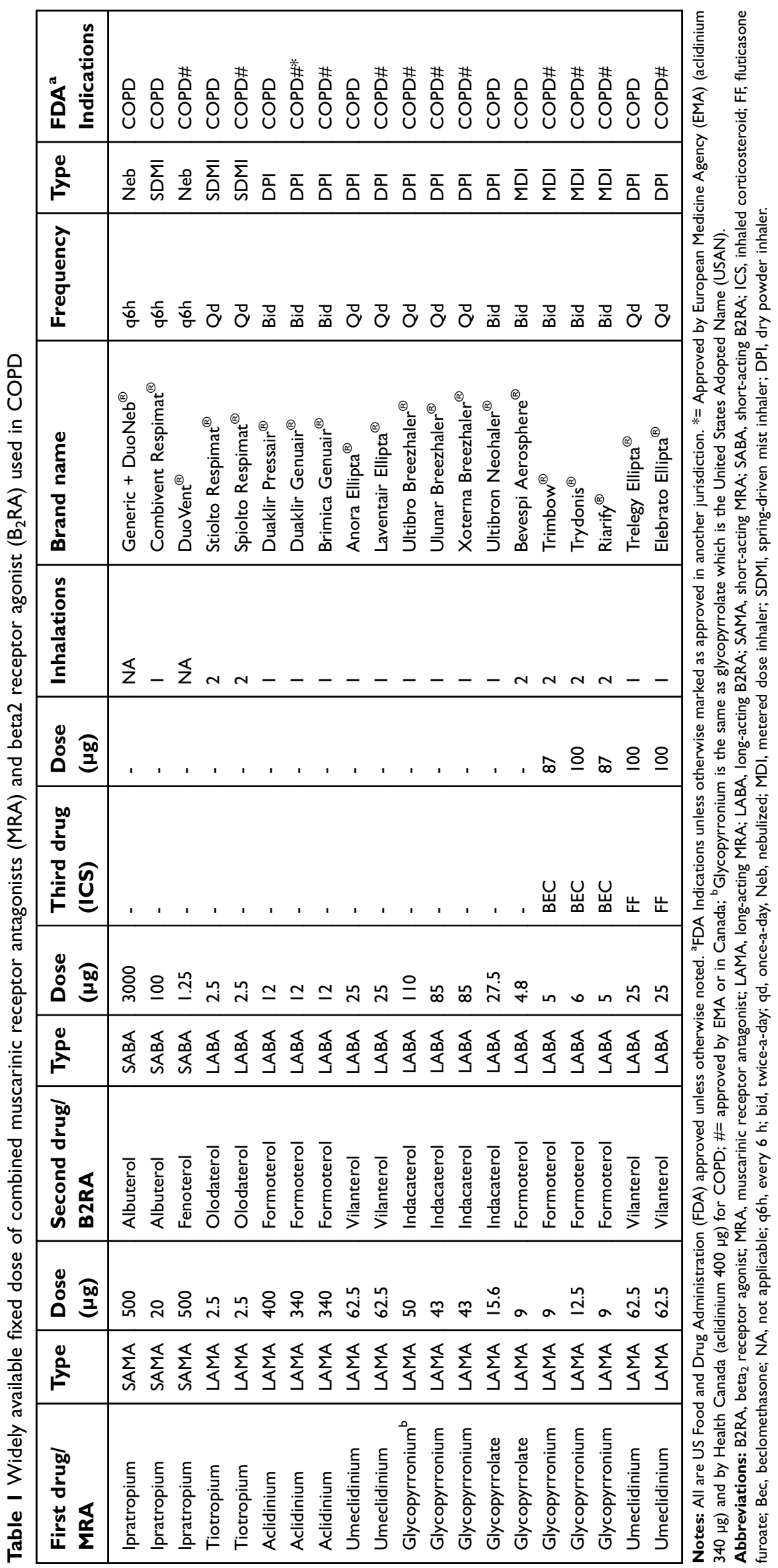




\begin{tabular}{|c|c|c|c|c|c|c|}
\hline 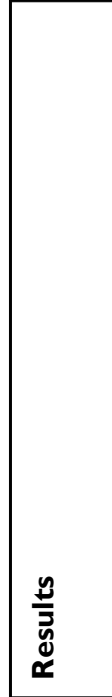 & 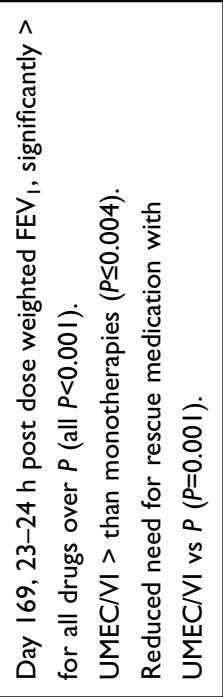 & 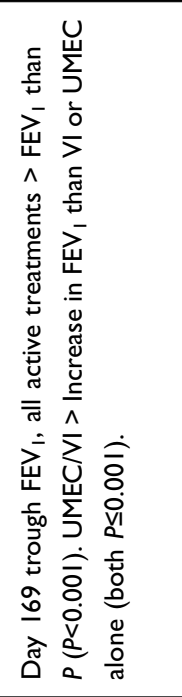 & 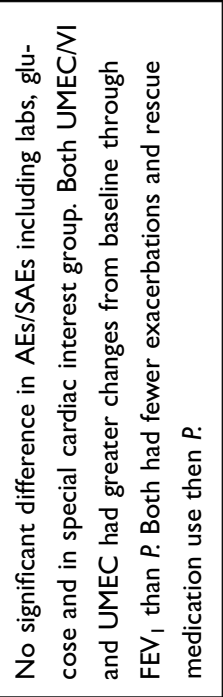 & 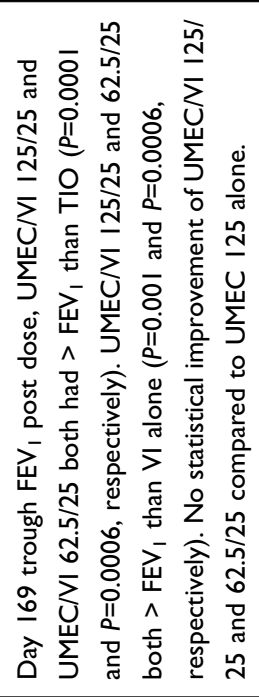 & 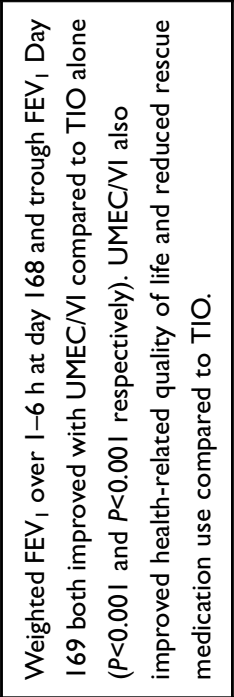 & 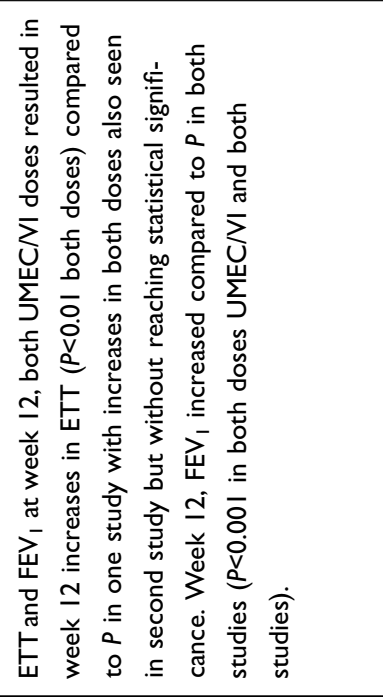 \\
\hline 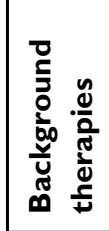 & 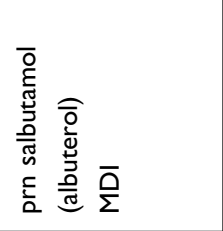 & 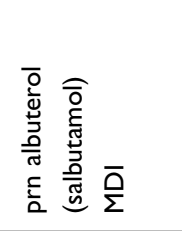 & 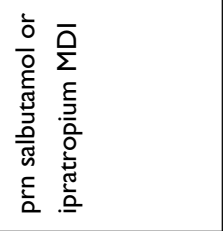 & 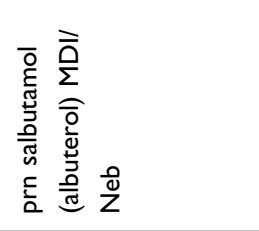 & 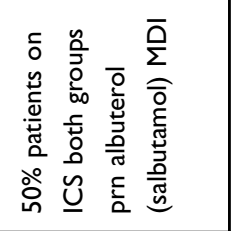 & 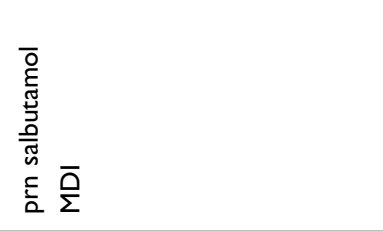 \\
\hline ڤัّ & $\bar{a}$ & $\bar{a}$ & $\bar{a}$ & $\bar{a}$ & $\bar{a}$ & $\bar{a}$ \\
\hline 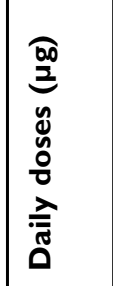 & 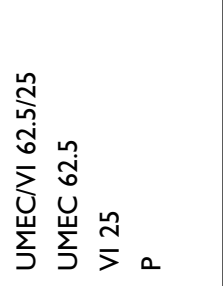 & 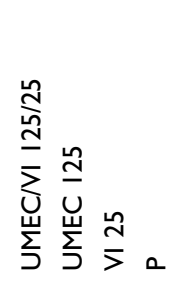 & 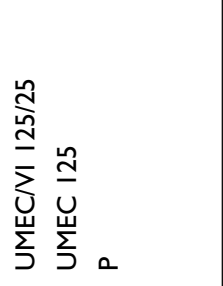 & 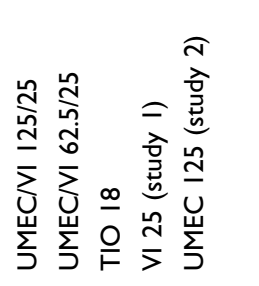 & 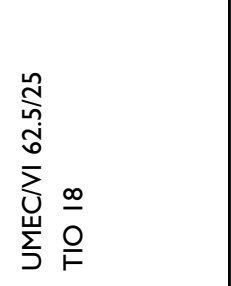 & 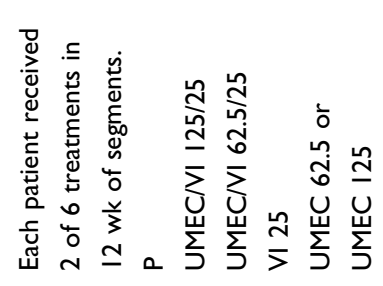 \\
\hline 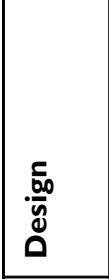 & 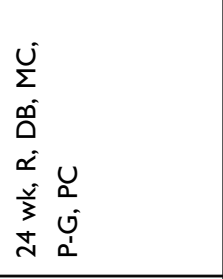 & 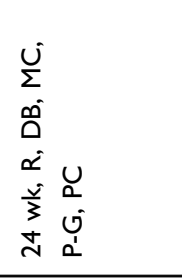 & 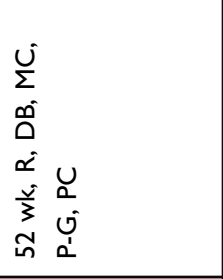 & 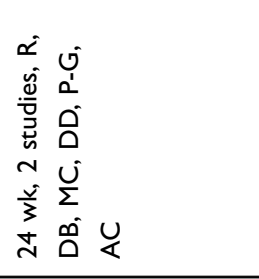 & 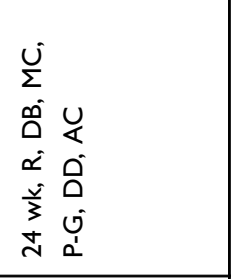 & 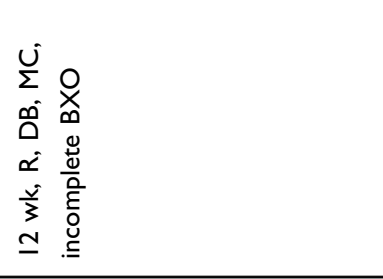 \\
\hline $\mathbf{z}$ & ָָ & 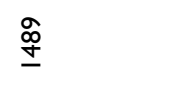 & గొ & $\underline{\underline{\Xi}} \underline{\underline{\Xi}}$ & 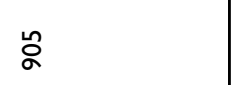 & 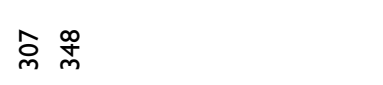 \\
\hline 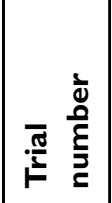 & $\begin{array}{l}\stackrel{0}{0} \\
\frac{0}{m} \\
\frac{m}{0} \\
\frac{0}{b}\end{array}$ & $\begin{array}{l}\hat{0} \\
\frac{0}{m} \\
\frac{m}{o} \\
\frac{b}{z}\end{array}$ & 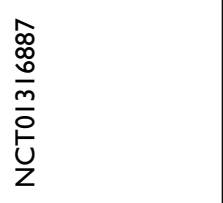 & 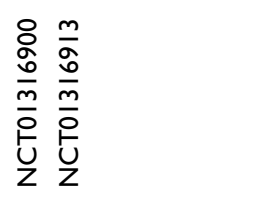 & 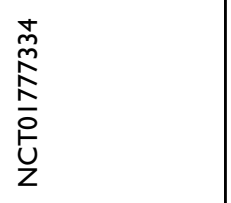 & 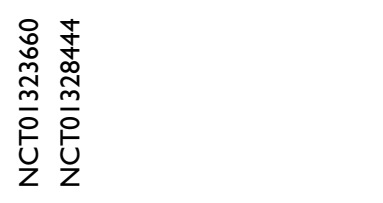 \\
\hline 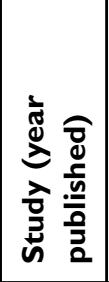 & 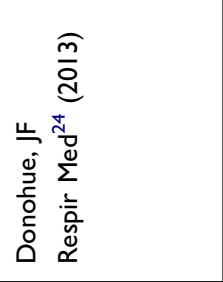 & 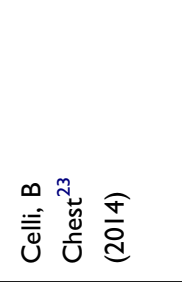 & 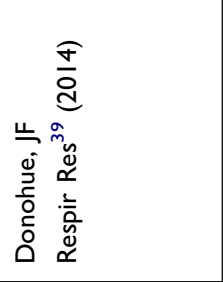 & 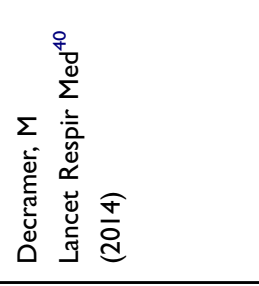 & 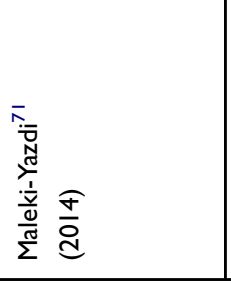 & 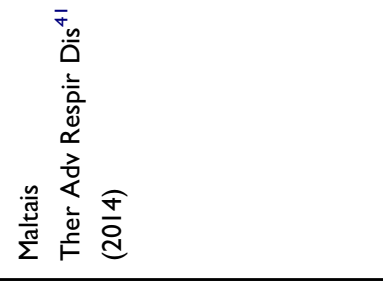 \\
\hline
\end{tabular}




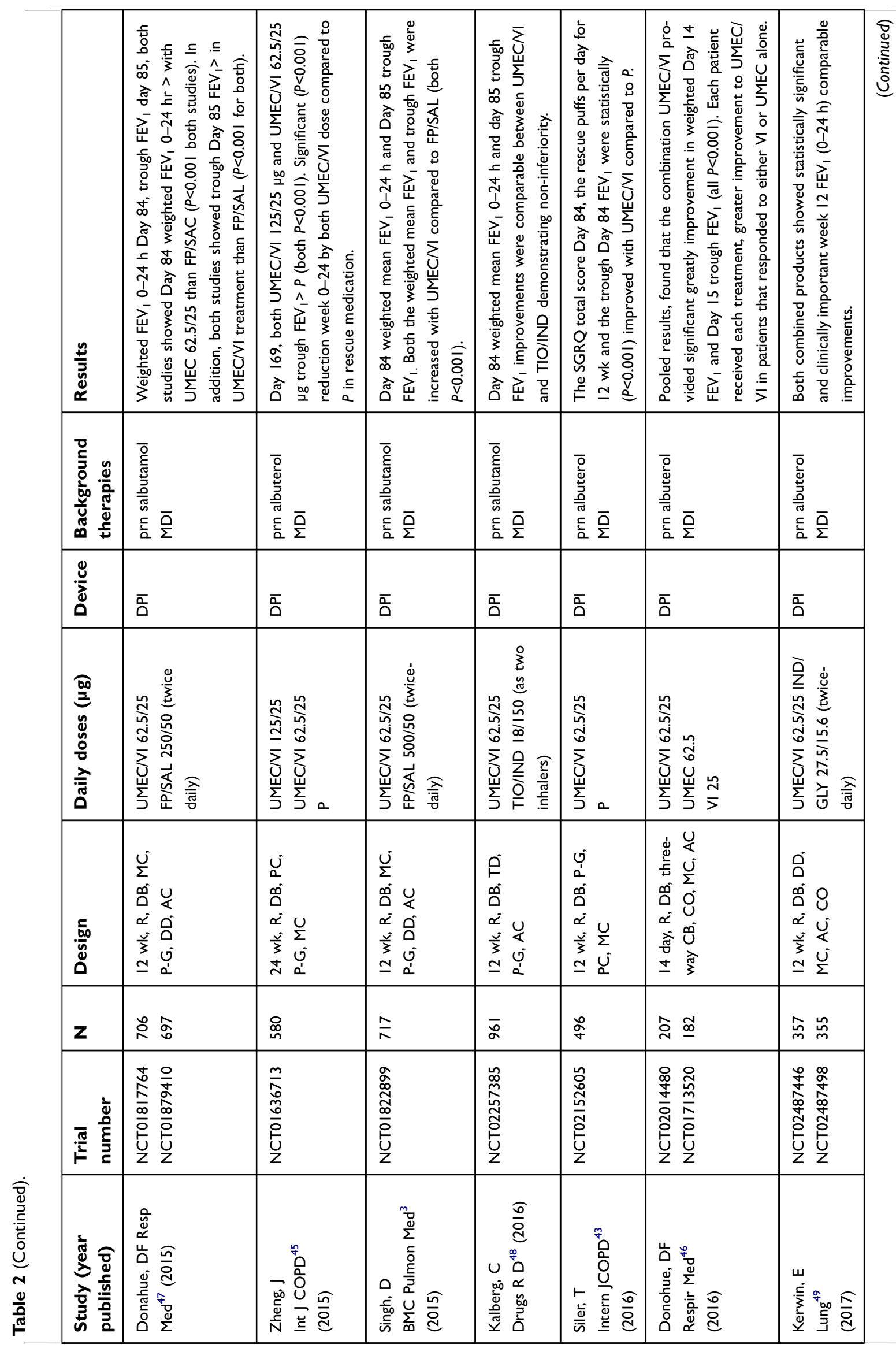




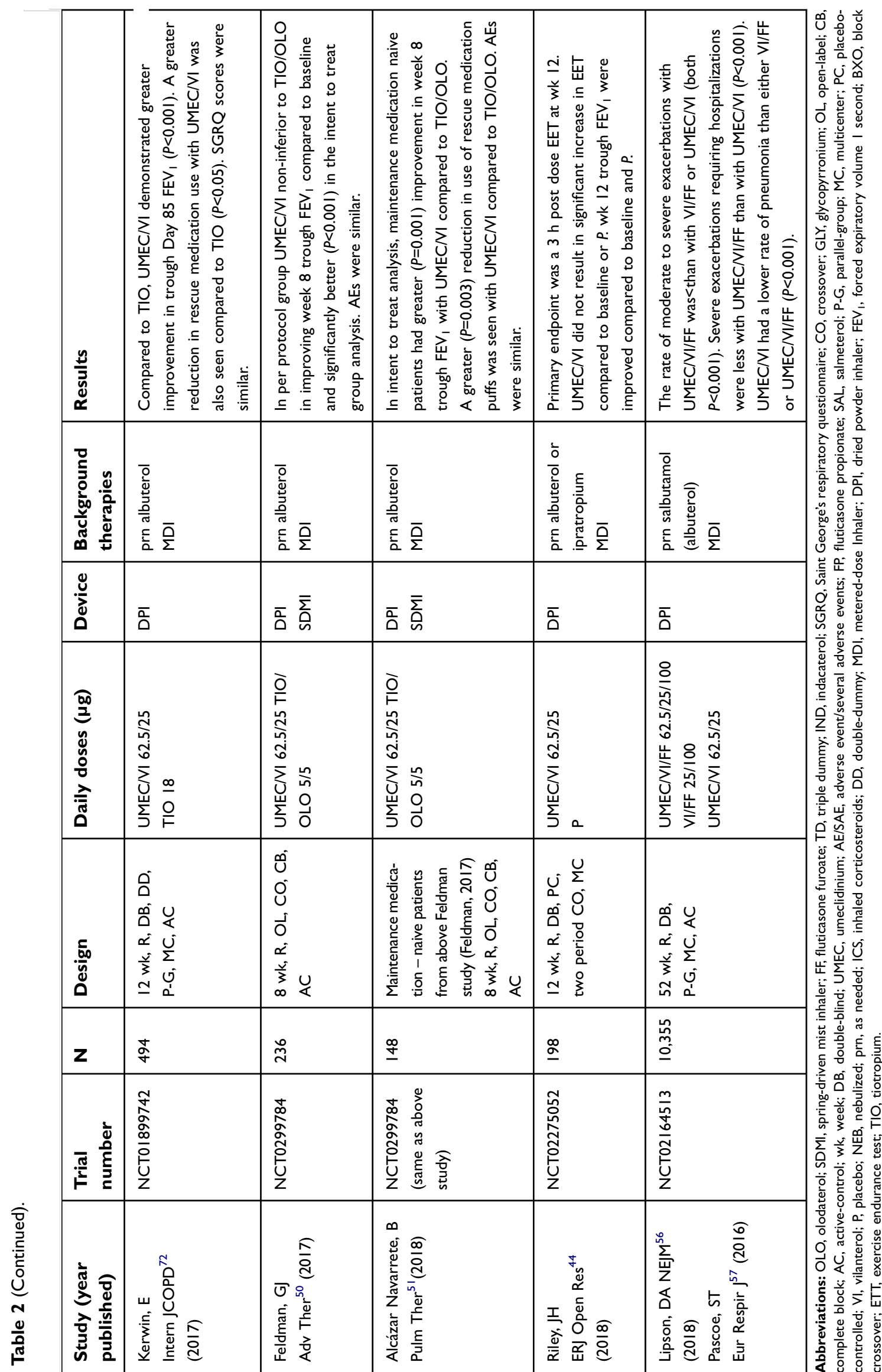


12-week trough $\mathrm{FEV}_{1} \cdot{ }^{3,47}$ In addition, a series of studies compared UMEC/VI $(62.5 / 25 \mu \mathrm{g})$ once daily to the LAMA tiotropium dry powder combined with the LABA indacaterol, the LAMA glycopyrronium also known as glycopyrrolate (GLY) combined with indacaterol (IND) as a DPI and tiotropium (TIO) combined with the LABA olodaterol (OLO) delivered by a spring-driven mist inhaler (Respimat $^{\circledR}$ ) once daily. ${ }^{4-51}$ In a 12-week, randomized, blinded, triple-dummy, parallel-group, non-inferiority trial, UMEC/VI $(62.5 / 25 \mu \mathrm{g})$ by DPI once daily was compared to with once-daily TIO $(18 \mu \mathrm{g})$ by DPI and once-daily indacaterol (IND; $150 \mu \mathrm{g}$ ) by DPI. ${ }^{28}$ The primary endpoint was trough Day $85 \mathrm{FEV}_{1}$ with UMEC/VI resulting in an average improvement from baseline of $0.172 \mathrm{~L}$ compared to TIO plus IND of $0.017 \mathrm{~L}(95 \% \mathrm{CI}, 0.029-0.030 \mathrm{~L})$. The treatments demonstrated non-inferiority and no difference in subjective measures, safety endpoints and COPD exacerbations. $^{28}$

The study by Kerwin ${ }^{29}$ evaluated once-daily DPI UMEC/VI $(62.5 / 25 \mu \mathrm{g})$ compared to twice-daily DPI GLY/IND (15.6/27.5 $\mu \mathrm{g})$ in two multiple-centered, doubleblind, double-dummy, cross-over studies in COPD patients. Inhalations were at home with the primary endpoint of $24 \mathrm{~h}$ of the area-under-curve $\left(\mathrm{AUC}_{0-24 \mathrm{~h}}\right)$ for $\mathrm{FEV}_{1}$ after 12 weeks of treatment. Both FDC LAMA/LABA inhalers demonstrated significant bronchodilation in $\mathrm{AUC}_{0-24 \mathrm{~h}}$ of $\mathrm{FEV}_{1}$ at week 12. Non-inferiority of IND/ GLY to UMEC/VI was not proven as the $\mathrm{FEV}_{1} \mathrm{AUC}_{0-24 \mathrm{~h}}$ at week 12 was 0.232 and $0.185 \mathrm{~L}$ improvement for GLY/ IND and 0.244 and $0.203 \mathrm{~L}$ with UMEC/VI29 These differences were statistically different in one iteration of the study, but not in the second, and the difference in $\mathrm{AUC}_{0-24 \mathrm{~h}} \mathrm{FEV}_{1}$ is probably not clinically significant.

An open-label, randomized, two-period, cross-over study of two different LAMA/LABA inhalers in patients with COPD compared once-daily UMEC/VI (62.5/ $25 \mu \mathrm{g})$ by DPI to once-daily TIO/OLO $(5 / 5 \mu \mathrm{g})$ by spring-driven "soft" mist inhaler (Respimat ${ }^{\circledR}$ ) each for 8 weeks with a 3 -week washout. ${ }^{30}$ The UMEC/VI treatment was non-inferior at week 8 trough $\mathrm{FEV}_{1}$. It was statistically superior to $\mathrm{TIO} / \mathrm{OLO}$ in the intent-to-treat population with an increase in week 8 trough $\mathrm{FEV}_{1}$ of $0.052 \mathrm{~L}(95 \% \mathrm{CI}$ of $0.028-0.077 \mathrm{~L} ; P<0.001)$. Clinical meaningful increases in the trough from baseline $\mathrm{FEV}_{1}$ of $0.100 \mathrm{~L}$ or more at week 8 were twice as likely to be reached with the use of UMEC/VI compared to TIO/ OLO treatments. Efficacy data from these trials demonstrated that the once-daily dry powder UMEC/VI
$(62.5 / 25 \mu \mathrm{g})$ was non-inferior or superior to the comparison treatment (Table 2).

A 12-week study on exercise tolerance demonstrated statistically increases with both $125 / 25 \mu \mathrm{g}$ and $62.5 / 25 \mu \mathrm{g}$ UMEC/VI inhaler doses compared to placebo inhaler in COPD patients with access to as-needed salbutamol. ${ }^{41}$ However, a recent study that evaluated UMEC/VI $(62.5 / 25 \mu \mathrm{g})$ compared to placebo in COPD patients with access to as-needed albuterol or ipratropium inhalers failed to show an improved in-exercise endurance testing despite improved trough $\mathrm{FEV}_{1}$ at week 12 . $^{44}$

Utilizing US health insurance plan data from 2013-2015, a large retrospective study examined COPD patients initiated on tiotropium or the combination UMEC/ VI and compared time to progression to triple-inhaled therapy of a LAMA, a LABA and an ICS. ${ }^{52}$ The study found that starting patients on tiotropium $(\mathrm{N}=35,357)$ was associated with an $87 \%$ higher risk of ending in triple therapy than those patients started on UMEC/VI $(\mathrm{N}=2407)(\mathrm{HR}=1.87,95 \% \mathrm{CI}, 1.4-2.5 P \geq 0.001)$. Another retrospective study evaluated COPD patients on commercial and Medicare Advantage Part D plans between 2014 and 2016. ${ }^{53}$ A sample of 2,200 COPD patients on UMEC/ VI was evaluated on the inhaler for a 12-month interval for COPD-related and all-cause medical costs, and risk of COPD exacerbations. ${ }^{53}$ Each month the patients were not on the UMEC/VI was associated with increased total medical costs with a $36.1 \%$ higher adjusted cost compared to those patients on the drug for the entire 12 months. The monthly severe exacerbation risk was also higher in those patients who had not yet started UMEC/VI $(\mathrm{HR}=1.74$, 95\% CI, 1.35-2.23, $P<0.001)$ during the 12-month study period. ${ }^{53}$ A single-center, retrospective, sequential, period analysis study of patients with COPD between 1 September 2015 and 29 February 2016 and 1 April 2016 to 30 September 2016 evaluated the incorporation of UMEC/VI into a standard COPD treatment protocol for hospitalized patients. ${ }^{54} \mathrm{~A}$ trend toward reduced readmission rates was seen after adding UMEC/ VI $(24.1 \%$ versus $10.8 \%)$ to the standard protocol but this was based on small patient numbers (pre-65 and post-58). When adjustments were made for confounders such as severity of illness, comorbidities, complications, and diagnosis-related group codes, the difference was not statistically significant (OR 2.499, 95\% CI, 0.916-7.380, $P=0.074$ ). Using a cost-effectiveness model, Wilson, et $\mathrm{al}^{55}$ predicted that in patients with moderate-to-very-severe COPD, significant lifetime cost savings would be seen 
using UMEC/VI compared to either tiotropium alone or separate LABA and LAMA inhalers. ${ }^{55}$

\section{Fixed-dose combination inhaler of UMEC/VI/fluticasone furoate}

The recently FDA-approved for COPD, once-daily, tripledrug, DPI (Trelegy Ellipta ${ }^{\circledR}$ ) with UMEC/VI/fluticasone furoate (FF) $(62.5 / 25 / 100 \mu \mathrm{g})$ was compared to UMEC/VI $(62.5 / 25 \mu \mathrm{g})$ or VI/FF $(25 / 100 \mu \mathrm{g})$ by DPI, once daily for 52 weeks in patients with COPD. ${ }^{56,57}$ This large study with more than 10,000 patients with COPD found that UMEC/VI/FF significantly reduced moderate-to-severe COPD exacerbations compared to either UMEC/VI or VI/FF (both $P<0.001$ ). Hospitalizations for severe COPD exacerbations were less with the triple inhaler compared to $\mathrm{UMEC} / \mathrm{VI}$, but the rate of pneumonia was less with UMEC/VI compared to either UMEC/VI/FF or VI/FF (both $P<0.001$ ). In addition to the FDC inhaler with UMEC/VI/FF, Table 1 lists additional FDC triple inhalers with the LAMA glycopyrronium, the LABA formoterol (FOR) and the ICS of beclomethasone (BEC) approved by the EMA for use in the European Union. A multi-center, parallel-group, double-blind, double-dummy "TRIBUTE" study of 1,432 symptomatic COPD patients was performed for 52 weeks comparing the FDC inhaler of once-daily GLY/IND $(43 / 85 \mu \mathrm{g})$ as a dry powder to a single FDC metered-dose inhaler GLY/FOR/BEC (9/5/87 $\mu \mathrm{g})$ two inhalations twice daily. ${ }^{58}$ The primary outcomes of moderate-to-severe COPD exacerbation rates were 0.50 per patient per year for the FDC GLY/FOR/BEC inhaler treatment and 0.59 per patient per year for the FDC GLY/IND (RR 0.848, 95\% CI, 0.723-0.995, $P=0.043$ ) in favor of the GLY/FOR/BEC inhaler treatment. The adverse events and rate of pneumonia were similar in the two treatment groups. ${ }^{58}$ The before study treatment eosinophil counts were similar (3.14\% GLY/FOR/BEC group and 2.97\% for the GLY/IND group) as was the number treated with ICS/LABA before study entry (both treatment groups $61 \%$ ). These two studies suggest there may be a role for adding an ICS as a single FDC inhaler in some COPD patients. The discordance of this data with the withdrawal of ICS studies may reflect different COPD patient populations tested. For example, as just noted, both treatment groups in the TRIBUTE study had mean elevated ( $\geq 2 \%)$ eosinophil counts pre-study drug suggesting there were many atopic or ACOS phenotype patients included. The exact phenotype of COPD patients that benefit from triple therapy that includes an ICS as opposed to the double therapy without an ICS is unclear.

A recent meta-analysis and systematic review found that the use of fixed-dose LAMA/LABA inhalers resulted in the greatest $\mathrm{FEV}_{1}$ improvement at weeks 12 and 24 in COPD patients compared to the use of a shortacting MRA (SAMA) alone, LAMA alone or fixed-dose ICS/LABA. ${ }^{59}$ Similarly, the current review of the efficacy of inhaled UMEC/VI confirms its effectiveness and safety in COPD patients. The recent study by Lipson et $\mathrm{al}^{56}$ showed that the triple inhaler of UMEC/VI/FF was superior to UMEC/VI in a large, 52-week-long trial. Again, the exact phenotypes of COPD that should be treated with a single inhaler (LAMA or LABA), double inhaler (LABA/ICS or LAMA/LABA) or a triple inhaler (LAMA/LABA/ICS as a single or multiple inhalers) as maintenance therapy are not well defined. A recent review has suggested that patients with a history of frequent COPD exacerbations, reduced health status, and impaired lung function in the presence of eosinophilic bronchial inflammation as evidenced by increased blood eosinophils or a history of asthma or ACOS may be the phenotype of COPD patients that respond to an ICS in combination with a LABA. ${ }^{60}$

Another review of the use of an ICS in COPD patients has suggested that they should not be used as a stand-alone maintenance therapy but rather used with a long-acting bronchodilator (LAMA or LABA). ${ }^{61}$ In this review, patients with frequent or severe COPD exacerbations after adherence to the use of maintenance bronchodilators particularly in patients with a history of asthma or blood eosinophils that are $>300$ cells $/ \mu \mathrm{L}$ are most likely to benefit from ICS. ${ }^{61}$ The risk of pneumonia in COPD patients treated with an ICS is higher in older age patients, those patients demonstrating greater fragility, patients with lower body mass index and in those patients with blood eosinophils $<100$ cells $/ \mu \mathrm{L} .^{61}$ A Cochrane review has confirmed that the use of an ICS in COPD patients is associated with an increased risk of pneumonia events but without significant increase in mortality. ${ }^{62}$

As noted, many COPD patients on ICS maintenance therapy tolerate the withdrawal of the ICS and the tolerance of this withdrawal may be dependent on disease severity, eosinophil counts, atopy, history of asthma, continued use of long-acting bronchodilators and whether there is evidence of hyper-responsive airways. ${ }^{63}$ Adding an ICS to a combination such as LAMA/LABA inhaler as another inhaler or as the FDC UMEC/VI/FF inhaler has 
been suggested in a recent meta-analysis in COPD patients that are on a single long-acting inhaler or on a combination LAMA/LABA inhaler and are still having frequent exacerbations and have a blood eosinophil count of $\geq 300$ cells $\mu \mathrm{L} .{ }^{64}$ How frequently and at what time intervals should step-down therapy or ICS withdrawal be attempted once triple-therapy is started in COPD patients is unclear.

\section{Ellipta ${ }^{\circledR}$ dry-powder inhaler device}

Little comprehensive clinical work has been done on inhaler devices used for COPD. Convenience, device/ drug availability, drug dose needed, ease of use and cost are some of the known variables. ${ }^{65}$ A systematic review of clinical outcomes and patient preferences with inhaler devices found that newer devices may improve patient satisfaction but so far fail to demonstrate any real clinical improvements. $^{66}$ One drug, tiotropium, requires a threefold reduction in dose when given by Respirmat ${ }^{\circledR}$ spring-driven mist device compared to the DPI Handihaler $^{\circledR}$ device, but no improved clinical outcomes were shown. ${ }^{66}$ Svedsater et $\mathrm{al}^{67}$ found the Ellipta ${ }^{\circledR}$ DPI device was associated with high satisfaction by users and preferred over many other inhalers. The Ellipta ${ }^{\circledR}$ DPI device was evaluated and found to be easy and intuitive to use and likely to improve adherence by COPD and asthma patient evaluators. ${ }^{67}$ A study by van der Palen ${ }^{68}$ tested COPD patients on inhaler use. This was a randomized, multi-center, open-label, placebo device study using a $2 \times 2$ complete-block design of a total of 159 patients. In one part of the study, the Ellipta ${ }^{\circledR}$ device was compared to the Turbuhaler ${ }^{\circledR}+$ Handihaler $^{\circledR}$ devices and the second part the Ellipta ${ }^{\circledR}$ device was compared to the Diskus ${ }^{\circledR}+$ Handihaler $^{\circledR}$ devices simulating triple-drug delivery with one device (Ellipta ${ }^{\circledR}$ ) compared to dual inhaler device combinations for the three drugs. The patients first read the package insert and were then tested on appropriateness of technique. Fewer patients made errors with the Ellipta ${ }^{\circledR}$ device compared to either the Diskus $^{\circledR}+$ Handihaler $^{\circledR}(9 \%$ (7/80) vs 75\% (16/80), respectively, $p<0.001)$ or the Turbuhaler ${ }^{\circledR}+$ Handihaler $^{\circledR}$ ( $9 \%$ (7/79) vs 73\% (58/79), respectively, $p<0.001)$. Shorter instruction time was required to correct poor technique with Ellipta ${ }^{\circledR}$ devices compared to the combination devices, and more patients preferred the Ellipta ${ }^{\circledR}$ device. Patient preference indicators were studied in COPD patients in the open-label randomized, cross-over trial of placebo-containing Ellipta ${ }^{\circledR}$ and Handihaler ${ }^{\circledR}$ dry powder devices. ${ }^{69}$ Significantly more of the 212 patients preferred the Ellipta ${ }^{\circledR}$ device to the Handihaler ${ }^{\circledR}$ device $(p<0.001)$. This study emphasizes that patient attitude toward a particular inhaler and their experiences using it may affect therapy adherence. ${ }^{69}$ A recent systematic review of 16 studies of both asthma and COPD patients reported that inhalation device errors were associated with worse disease outcomes. ${ }^{70}$ Education time invested in improving inhalation technique in COPD can improve health outcomes. However, improved clinical outcomes with this device over other delivery devices with UMEC/VI have not been shown to date.

\section{Conclusions}

The fixed-dose DPI LAMA/LABA inhaler with UMEC and VI $(62.5 / 25 \mu \mathrm{g})$ offers an important option in a stepwise treatment approach to the COPD patient. The use of UMEC/VI DPI in COPD has significant data supporting its efficacy and defining its risks. It is well tolerated, and the Ellipta $^{\circledR}$ delivery system is liked by COPD patients. Improved drug use adherence and reduced drug delivery errors are expected with the Ellipta ${ }^{\circledR}$ device based on studies available. FDC inhalers that contain LAMA/ LABA components are a mainstay in the treatment of COPD. These combination agents routinely result in lower total co-payments for patients with COPD in managed-care and straight insurance programs.

\section{Disclosure}

The authors report no conflicts of interest in this work.

\section{References}

1. Decramer M, Janssens W, Miravitlles M. Chronic obstructive pulmonary disease. Lancet. 2012;379(9823):1341-1351. doi:10.1016/S01406736(11)60968-9

2. Oba Y, Sarva ST, Dias S. Efficacy and safety of long-acting beta-agonist/ long-acting muscarinic antagonist combinations in COPD: a network meta-analysis. Thorax. 2016;71(1):15-25. doi:10.1136/thoraxjnl-2014206732

3. Singh D. New combination bronchodilators for chronic obstructive pulmonary disease: current evidence and future perspectives. $\mathrm{Br}$ J Clin Pharmacol. 2015;79(5):695-708. doi:10.1111/bcp.12545

4. Calzetta L, Rogliani P, Matera MG, Cazzola M. A systematic review with meta-analysis of dual bronchodilation with LAMA/LABA for the treatment of stable COPD. Chest. 2016;149(5):1181-1196. doi:10.1016/j. chest.2016.02.646

5. Price D, Ostrem A, Thomas M, Welte T. Dual bronchodilation in COPD: lung function and patient-reported outcomes - a review. Int J Chron Obstruct Pulmon Dis. 2017;12:141-168. doi:10.2147/ COPD.S116719

6. Rodrigo GJ, Price D, Anzueto A, et al. LABA/LAMA combinations versus LAMA monotherapy or LABA/ICS in COPD: a systematic review and meta-analysis. Int $J$ Chron Obstruct Pulmon Dis. 2017;12:907-922. doi:10.2147/COPD.S130482 
7. Horita N, Goto A, Shibata Y, et al. Long-acting muscarinic antagonist (LAMA) plus long-acting beta-agonist (LABA) versus LABA plus inhaled corticosteroid (ICS) for stable chronic obstructive pulmonary disease (COPD). Cochrane Database Syst Rev. 2017;2:CD012066.

8. Magnussen H, Disse B, Rodriguez-Roisin R, et al. Withdrawal of inhaled glucocorticoids and exacerbations of COPD. $N$ Engl J Med. 2014;371(14):1285-1294. doi:10.1056/NEJMoa1407154

9. Chapman KR, Hurst JR, Frent SM, et al. Long-term triple therapy de-escalation to Indacaterol/Glycopyrronium in patients with chronic obstructive pulmonary disease (SUNSET): a randomized, double-blind, triple-dummy clinical trial. Am J Respir Crit Care Med. 2018;198(3):329-339. doi:10.1164/rccm.201803-0405OC

10. Cheng SL. Blood eosinophils and inhaled corticosteroids in patients with COPD: systematic review and meta-analysis. Int J Chron Obstruct Pulmon Dis. 2018;13:2775-2784. doi:10.2147/COPD. S175017

11. Singh A, Liu C, Putman B, et al. Predictors of Asthma/COPD overlap in FDNY firefighters with world trade center dust exposure: a longitudinal study. Chest. 2018;154(6):1301-1310. doi:10.1016/j. chest.2018.07.002

12. Cataldo D, Corhay JL, Derom E, et al. A Belgian survey on the diagnosis of asthma-COPD overlap syndrome. Int J Chron Obstruct Pulmon Dis. 2017;12:601-613. doi:10.2147/COPD.S124459

13. Donohue JF, Anzueto A, Brooks J, Mehta R, Kalberg C, Crater G. A randomized, double-blind dose-ranging study of the novel LAMA GSK573719 in patients with COPD. Respir Med. 2012;106 (7):970-979. doi:10.1016/j.rmed.2012.03.012

14. Pleasants RA, Wang T, Gao J, Tang H, Donohue JF. Inhaled umeclidinium in COPD patients: a review and meta-analysis. Drugs 2016;76(3):343-361. doi:10.1007/s40265-015-0532-5

15. Rheault T, Khindri S, Vahdati-Bolouri M, Church A, Fahy WA. A randomised, open-label study of umeclidinium versus glycopyrronium in patients with COPD. ERJ Open Res. 2016;2(2):00101-2015. doi:10.1183/23120541.00101-2015

16. Babu KS, Morjaria JB. Umeclidinium in chronic obstructive pulmonary disease: latest evidence and place in therapy. Ther Adv Chronic Dis. 2017;8(4-5):81-91. doi:10.1177/2040622317700822

17. Feldman G, Maltais F, Khindri S, et al. A randomized, blinded study to evaluate the efficacy and safety of umeclidinium $62.5 \mathrm{mug}$ compared with tiotropium 18 mug in patients with COPD. Int J Chron Obstruct Pulmon Dis. 2016;11:719-730. doi:10.2147/COPD. S102494

18. Hanania NA, Feldman G, Zachgo W, et al. The efficacy and safety of the novel long-acting beta 2 agonist vilanterol in patients with COPD: a randomized placebo-controlled trial. Chest. 2012;142(1):119-127. doi:10.1378/chest.11-2231

19. Kempsford R, Norris V, Siederer S. Vilanterol trifenatate, a novel inhaled long-acting beta2 adrenoceptor agonist, is well tolerated in healthy subjects and demonstrates prolonged bronchodilation in subjects with asthma and COPD. Pulm Pharmacol Ther. 2013;26 (2):256-264. doi:10.1016/j.pupt.2012.12.001

20. Malerba M, Radaeli A, Montuschi P, Morjaria JB. Vilanterol trifenatate for the treatment of COPD. Expert Rev Respir Med. 2016;10 (7):719-731. doi:10.1080/17476348.2016.1184976

21. Calzetta L, Rogliani P, Facciolo F, Rendina E, Cazzola M, Matera MG. Pharmacological characterization of the interaction between umeclidinium and vilanterol in human bronchi. Eur J Pharmacol. 2017;812:147-154. doi:10.1016/j.ejphar.2017.07.026

22. Shaikh N, Johnson M, Hall DA, et al. Intracellular interactions of umeclidinium and vilanterol in human airway smooth muscle. Int J Chron Obstruct Pulmon Dis. 2017;12:1903-1913. doi:10.2147/ COPD.S134420

23. Celli B, Crater G, Kilbride S, et al. Once-daily umeclidinium/vilanterol 125/25 mcg in COPD: a randomized, controlled study. Chest 2014;145(5):981-991. doi:10.1378/chest.13-1579
24. Donohue JF, Maleki-Yazdi MR, Kilbride S, Mehta R, Kalberg C, Church A. Efficacy and safety of once-daily umeclidinium/vilanterol 62. 5/25mcg in COPD. Respir Med. 2013;107(10):1538-1546. doi:10.1016/j.rmed.2013.06.001

25. Goyal N, Beerahee M, Kalberg C, Church A, Kilbride S, Mehta R. Population pharmacokinetics of inhaled umeclidinium and vilanterol in patients with chronic obstructive pulmonary disease. Clin Pharmacokinet. 2014;53(7):637-648. doi:10.1007/s40262-014-0143-4

26. Kelleher DL, Mehta RS, Jean-Francois BM, et al. Safety, tolerability, pharmacodynamics and pharmacokinetics of umeclidinium and vilanterol alone and in combination: a randomized crossover trial. PLoS One. 2012;7(12):e50716.

27. $\mathrm{Hu} \mathrm{C}$, Jia J, Dong K, et al. Pharmacokinetics and tolerability of inhaled umeclidinium and vilanterol alone and in combination in healthy Chinese subjects: a randomized, open-label, crossover trial. PLoS One. 2015;10(3):e0121264. doi:10.1371/journal. pone. 0121264

28. Feldman G, Walker RR, Brooks J, Mehta R, Crater G. 28-Day safety and tolerability of umeclidinium in combination with vilanterol in COPD: a randomized placebo-controlled trial. Pulm Pharmacol Ther. 2012;25(6):465-471. doi:10.1016/j.pupt.2012.08.007

29. Mehta R, Hardes K, Brealey N, Tombs L, Preece A, Kelleher D. Effect of severe renal impairment on umeclidinium and umeclidinium/vilanterol pharmacokinetics and safety: a single-blind, nonrandomized study. Int J Chron Obstruct Pulmon Dis. 2015;10:15-23. doi:10.2147/COPD.S68094

30. Mehta R, Hardes K, Kelleher D, Preece A, Tombs L, Brealey N. Effects of moderate hepatic impairment on the pharmacokinetic properties and tolerability of umeclidinium and vilanterol in inhalational umeclidinium monotherapy and umeclidinium/vilanterol combination therapy: an open-label, nonrandomized study. Clin Ther. 2014;36(7):1016-1027 e1012. doi:10.1016/j. clinthera.2014.05.002

31. Mehta R, Kelleher D, Preece A, Hughes S, Crater G. Effect of verapamil on systemic exposure and safety of umeclidinium and vilanterol: a randomized and open-label study. Int J Chron Obstruct Pulmon Dis. 2013;8:159-167. doi:10.2147/COPD.S40859

32. Kelleher D, Tombs L, Preece A, Brealey N, Mehta R. A randomized, placebo- and moxifloxacin-controlled thorough QT study of umeclidinium monotherapy and umeclidinium/vilanterol combination in healthy subjects. Pulm Pharmacol Ther. 2014;29(1):49-57. doi:10.1016/j.pupt.2014.07.002

33. Rodrigo GJ, Neffen $\mathrm{H}$. A systematic review of the efficacy and safety of a fixed-dose combination of umeclidinium and vilanterol for the treatment of COPD. Chest. 2015;148(2):397-407. doi:10.1378/chest.15-0084

34. Rogliani P, Ora J, Matera MG, Cazzola M, Calzetta L. The safety of dual bronchodilation on cardiovascular serious adverse events in COPD. Expert Opin Drug Saf. 2018;17(6):589-596. doi:10.1080/ 14740338.2018.1472232

35. Feldman GJ, Edin A. The combination of umeclidinium bromide and vilanterol in the management of chronic obstructive pulmonary disease: current evidence and future prospects. Ther Adv Respir Dis. 2013;7(6):311-319. doi:10.1177/1753465813499789

36. Malerba M, Morjaria JB, Radaeli A. Differential pharmacology and clinical utility of emerging combination treatments in the management of COPD-role of umeclidinium/vilanterol. Int J Chron Obstruct Pulmon Dis. 2014;9:687-695. doi:10.2147/COPD.S47792

37. Albertson TE, Harper R, Murin S, Sandrock C. Patient considerations in the treatment of COPD: focus on the new combination inhaler umeclidinium/vilanterol. Patient Prefer Adherence. 2015;9:235-242. doi:10.2147/PPA.S71535

38. Ray R, Tombs L, Asmus MJ, et al. Efficacy of Umeclidinium/ Vilanterol in elderly patients with COPD: a pooled analysis of randomized controlled trials. Drugs Aging. 2018;35(7):637-647. doi:10.1007/s40266-018-0558-y 
39. Donohue JF, Niewoehner D, Brooks J, O'Dell D, Church A. Safety and tolerability of once-daily umeclidinium/vilanterol $125 / 25 \mathrm{mcg}$ and umeclidinium $125 \mathrm{mcg}$ in patients with chronic obstructive pulmonary disease: results from a 52-week, randomized, double-blind, placebo-controlled study. Respir Res. 2014;15:78. doi:10.1186/1465-9921-15-78

40. Decramer M, Anzueto A, Kerwin E, et al. Efficacy and safety of umeclidinium plus vilanterol versus tiotropium, vilanterol, or umeclidinium monotherapies over 24 weeks in patients with chronic obstructive pulmonary disease: results from two multicentre, blinded, randomised controlled trials. Lancet Respir Med. 2014;2(6):472-486. doi:10.1016/S2213-2600(14)70065-7

41. Maltais F, Singh S, Donald AC, et al. Effects of a combination of umeclidinium/vilanterol on exercise endurance in patients with chronic obstructive pulmonary disease: two randomized, double-blind clinical trials. Ther Adv Respir Dis. 2014;8 (6):169-181. doi:10.1177/1753465814559209

42. F.D.A. U.S. Food and Drug Administration. 2018. Available from: https://www.accessdata.fda.gov/scripts/cder/daf/index.cfm?event=overview.process\&ApplNo=203975. Accessed November 29, 2018.

43. Siler TM, Donald AC, O'Dell D, Church A, Fahy WA. A randomized, parallel-group study to evaluate the efficacy of umeclidinium/vilanterol $62.5 / 25 \mathrm{mug}$ on health-related quality of life in patients with COPD. Int $J$ Chron Obstruct Pulmon Dis. 2016;11:971-979. doi:10.2147/COPD.S102962

44. Riley JH, Kalberg CJ, Donald A, Lipson DA, Shoaib M, Tombs L. Effects of umeclidinium/vilanterol on exercise endurance in COPD: a randomised study. ERJ Open Res. 2018;4(1):00073-2017. doi:10.1183/23120541.00073-2017

45. Zheng J, Zhong N, Newlands A, Church A, Goh AH. Efficacy and safety of once-daily inhaled umeclidinium/vilanterol in Asian patients with COPD: results from a randomized, placebo-controlled study. Int J Chron Obstruct Pulmon Dis. 2015;10:1753-1767. doi:10.2147/COPD.S81053

46. Donohue JF, Singh D, Munzu C, Kilbride S, Church A. Magnitude of umeclidinium/vilanterol lung function effect depends on monotherapy responses: results from two randomised controlled trials. Respir Med. 2016;112:65-74. doi:10.1016/j.rmed.2016.01.001

47. Donohue JF, Worsley S, Zhu CQ, Hardaker L, Church A. Improvements in lung function with umeclidinium/vilanterol versus fluticasone propionate/salmeterol in patients with moderate-to-severe COPD and infrequent exacerbations. Respir Med. 2015;109 (7):870-881. doi:10.1016/j.rmed.2015.04.018

48. Kalberg C, O'Dell D, Galkin D, Newlands A, Fahy WA. Dual bronchodilator therapy with Umeclidinium/Vilanterol versus tiotropium plus indacaterol in chronic obstructive pulmonary disease: a randomized controlled trial. Drugs $R$ D. 2016;16(2):217-227. doi:10.1007/s40268-016-0131-2

49. Kerwin E, Ferguson GT, Sanjar S, et al. Dual bronchodilation with indacaterol Maleate/Glycopyrronium bromide compared with umeclidinium bromide/vilanterol in patients with moderate-to-severe COPD: results from two randomized, controlled, cross-over studies. Lung. 2017;195(6):739-747. doi:10.1007/s00408-017-0055-9

50. Feldman GJ, Sousa AR, Lipson DA, et al. Comparative efficacy of once-daily Umeclidinium/Vilanterol and Tiotropium/Olodaterol therapy in symptomatic chronic obstructive pulmonary disease: a randomized study. Adv Ther. 2017;34(11):2518-2533. doi:10.1007/s12325-0170626-4

51. Alcázar Navarrete B, Boucot I, Naya I, et al. Umeclidinium/ Vilanterol versus Tiotropium/Olodaterol in maintenance-naïve patients with moderate symptomatic chronic obstructive pulmonary disease: a post hock analysis. Pulm Ther. 2018;4:171-183. doi.org/ 10.1007/s41030-018-0057-7.

52. Hahn B, Hull M, Blauer-Peterson C, Buikema AR, Ray R, Stanford RH. Rates of escalation to triple COPD therapy among incident users of LAMA and LAMA/LABA. Respir Med. 2018;139:65-71. doi:10.1016/j.rmed.2018.04.014
53. Buikema AR, Brekke L, Anderson A, et al. The effect of delaying initiation with umeclidinium/vilanterol in patients with COPD: an observational administrative claims database analysis using marginal structural models. Multidiscip Respir Med. 2018;13:38. doi:10.1186/ s40248-018-0151-6

54. Chapin TW, Mann MA, Brown GL, Leitheiser TL, Anderson B, Leedahl DD. Effectiveness of umeclidinium-vilanterol for protocolized management of chronic obstructive pulmonary disease exacerbation in hospitalized patients: a sequential period analysis. Chronic Obstr Pulm Dis. 2018;5(1):38-45. doi:10.15326/jcopdf.5.1.2017. 0163

55. Wilson MR, Patel JG, Coleman A, McDade CL, Stanford RH, Earnshaw SR. Cost-effectiveness analysis of umeclidinium/vilanterol for the management of patients with moderate to very severe COPD using an economic model. Int $J$ Chron Obstruct Pulmon Dis. 2017;12:997-1008. doi:10.2147/COPD.S124420

56. Lipson DA, Barnhart F, Brealey N, et al. Once-daily single-inhaler triple versus dual therapy in patients with COPD. $N$ Engl J Med. 2018;378(18):1671-1680. doi:10.1056/NEJMoa1713901

57. Pascoe SJ, Lipson DA, Locantore N, et al. A phase III randomised controlled trial of single-dose triple therapy in COPD: the IMPACT protocol. Eur Respir J. 2016;48(2):320-330. doi:10.1183/ 13993003.02165-2015

58. Papi A, Vestbo J, Fabbri L, et al. Extrafine inhaled triple therapy versus dual bronchodilator therapy in chronic obstructive pulmonary disease (TRIBUTE): a double-blind, parallel group, randomised controlled trial. Lancet. 2018;391(10125):1076-1084. doi:10.1016/ S0140-6736(18)30206-X

59. Aziz MIA, Tan LE, Wu DB, et al. Comparative efficacy of inhaled medications (ICS/LABA, LAMA, LAMA/LABA and SAMA) for COPD: a systematic review and network meta-analysis. Int $J$ Chron Obstruct Pulmon Dis. 2018;13:3203-3231. doi:10.2147/COPD. S173472

60. Tashkin DP, Strange C. Inhaled corticosteroids for chronic obstructive pulmonary disease: what is their role in therapy? Int $J$ Chron Obstruct Pulmon Dis. 2018;13:2587-2601. doi:10.2147/COPD. S172240

61. Agusti A, Fabbri LM, Singh D, et al. Inhaled corticosteroids in COPD: friend or foe? Eur Respir J. 2018;52:1801219. doi:10.1183/ 13993003.01219-2018

62. Kew KM, Seniukovich A. Inhaled steroids and risk of pneumonia for chronic obstructive pulmonary disease. Cochrane Database Syst Rev. 2014;(3):CD010115. doi:10.1002/146518558.CD010115.pub2.

63. Ye W, Guo X, Yang T, Han F. Systematic review of inhaled corticosteroid withdrawal effects in chronic obstructive pulmonary disease, and comparison with two "real-life" studies. J Thorac Dis. 2018;10(7):4565-4573. doi:10.21037/jtd.2018.06.151

64. Cazzola M, Rogliani P, Calzetta L, Matera MG. Triple therapy versus single and dual long-acting bronchodilator therapy in chronic obstructive pulmonary disease: a systematic review and meta-analysis. Eur Respir J. 2018;52:1801586. doi:10.1183/ 13993003.01586-2018

65. Dolovich MB, Ahrens RC, Hess DR, et al. Device selection and outcomes of aerosol therapy: evidence-based guidelines: American College of Chest Physicians/American College of Asthma, Allergy, and Immunology. Chest. 2005;127(1):335-371. doi:10.1378/ chest.127.1.335

66. Ninane V, Vandevoorde J, Cataldo D, et al. New developments in inhaler devices within pharmaceutical companies: a systematic review of the impact on clinical outcomes and patient preferences. Respir Med. 2015;109(11):1430-1438. doi:10.1016/j.rmed.2015.09.013

67. Svedsater H, Dale P, Garrill K, Walker R, Woepse MW. Qualitative assessment of attributes and ease of use of the ELLIPTA dry powder inhaler for delivery of maintenance therapy for asthma and COPD. BMC Pulm Med. 2013;13:72. doi:10.1186/ $1471-2466-13-72$ 
68. van der Palen J, Moeskops-van Beurden W, Dawson CM, et al A randomized, open-label, single-visit, crossover study simulating triple-drug delivery with Ellipta compared with dual inhaler combinations in patients with COPD. Int $J$ Chron Obstruct Pulmon Dis. 2018;13:2515-2523. doi:10.2147/COPD.S169060

69. Collison KA, Patel P, Preece AF, Stanford RH, Sharma RK, Feldman G. A randomized clinical trial comparing the ELLIPTA and handihaler dry powder inhalers in patients with COPD: inhaler-specific attributes and overall patient preference. Copd. 2018;15(1):46-50. doi:10.1080/15412555.2017.1400000

70. Kocks JWH, Chrystyn H, van der Palen J, et al. Systematic review of association between critical errors in inhalation and health outcomes in asthma and COPD. NPJ Prim Care Respir Med. 2018;28(1):43. doi: 10.1038/s41533-018-0110-x
71. Maleki-Yazdi MR, Kaelin T, Richard N, Zvarich M, Church A. Efficacy and safety of umeclidinium/vilanterol $62.5 / 25 \mathrm{mcg}$ and tiotropium $18 \mathrm{mcg}$ in chronic obstructive pulmonary disease: results of a 24-week, randomized, controlled trial. Respir Med. 2014;108 (12):1752-1760. doi:10.1016/j.rmed.2014.10.002

72. Kerwin EM, Kalberg CJ, Galkin DV, et al. Umeclidinium/vilanterol as step-up therapy from tiotropium in patients with moderate COPD: a randomized, parallel-group, 12-week study. Int J Chron Obstruct Pulmon Dis. 2017;12:745-755. doi:10.2147/COPD.S119032

\section{Publish your work in this journal}

The International Journal of COPD is an international, peer-reviewed journal of therapeutics and pharmacology focusing on concise rapid reporting of clinical studies and reviews in COPD. Special focus is given to the pathophysiological processes underlying the disease, intervention programs, patient focused education, and self management protocols. This journal is indexed on PubMed Central, MedLine and CAS. The manuscript management system is completely online and includes a very quick and fair peer-review system, which is all easy to use. Visit http://www.dovepress.com/testimonials.php to read real quotes from published authors. 